\title{
Correction
}

\section{Correction to: SPEXOR: Design and development of passive spinal exoskeletal robot for low back pain prevention and vocational reintegration}

\author{
Jan Babič ${ }^{1}$ Idsart Kingma ${ }^{2}$ Jonas Bornmann ${ }^{3} \cdot$ Katja Mombaur $^{4} \cdot$ Matthias Näf ${ }^{5}$. Tadej Petrič ${ }^{1} \cdot$ Han Houdijk ${ }^{2,6}$. \\ Jose González-Vargas ${ }^{3} \cdot$ Saskia Baltrusch $^{6} \cdot$ Nejc Šarabon $^{7,8}$
}

(c) The Author(s) 2019 OPEN

\section{Correction to: SN Applied Sciences (2019) 1:262 \\ https://doi.org/10.1007/s42452-019-0266-1}

The list of authors and some of the authors' affiliations Publisher's Note Springer Nature remains neutral with regard to were incorrect in the original publication. The correct author list and authors' affiliations are shown here.

Open Access This article is distributed under the terms of the Creative Commons Attribution 4.0 International License (http://creativeco mmons.org/licenses/by/4.0/), which permits unrestricted use, distribution, and reproduction in any medium, provided you give appropriate credit to the original author(s) and the source, provide a link to the Creative Commons license, and indicate if changes were made.

The original article can be found online at https://doi.org/10.1007/s42452-019-0266-1.

Jan Babič, jan.babic@ijs.si | ${ }^{1}$ Laboratory for Neuromechanics and Biorobotics, Jožef Stefan Institute, Ljubljana, Slovenia. ${ }^{2}$ Department of Human Movement Sciences, Vrije Universiteit, Amsterdam Movement Sciences, Amsterdam, The Netherlands. ${ }^{3} \mathrm{Global}$ Research \& Innovation, Ottobock SE \& Co. KGaA, Duderstadt, Germany. ${ }^{4}$ Institute of Computer Engineering, Optimization, Robotics and Biomechanics Group, Heidelberg University, Heidelberg, Germany. ${ }^{5}$ Robotics and Multibody Mechanics Research Group, Vrije Universiteit Brussel, Brussels, Belgium. ${ }^{6}$ Department of Research and Development, Heliomare Rehabilitation, Wijk aan Zee, The Netherlands. ${ }^{7}$ S2P, Science to Practice, Ltd., Ljubljana, Slovenia. ${ }^{8}$ Faculty of Health Sciences, University of Primorska, Koper, Slovenia. 